Cuadernos de Filología Clásica. Estudios Latinos ISSN: 1131-9062

http://dx.doi.org/10.5209/CFCL.62522

\title{
Séneca, (San) Hipólito y Prudencio: una recapitulación
}

\author{
Emilio del Río Sanz ${ }^{1}$
}

Recibido: 20 de septiembre de 2018 / Aceptado: 21 de noviembre de 2018

Resumen. Es un hecho recogido por la crítica ya en el siglo XIX que el martirio de San Hipólito, tal y como lo relata Prudencio en el poema 11 de su Peristephanon, guarda evidentes similitudes con la suerte que corre Hipólito en la mitología clásica y, en particular, con la versión de ello que presenta Séneca en su tragedia Phaedra. Este trabajo estudia los puntos en común de estructura y contenido entre ambos textos, analiza los pasajes correspondientes y se detiene en revisar la bibliografía al respecto de los últimos treinta años. Se puede concluir de todo ello que Prudencio construye su poema sobre la écfrasis de un fresco realmente existente en el que se reflejaba el martirio del santo en términos coincidentes con el relato senecano, y que lo que persigue con ello es proponer la figura de un mártir cristiano que, en su construcción literaria, asimila y supera los rasgos del héroe épico, del héroe trágico y del sabio estoico. Palabras clave: Séneca; Prudencio; Fedra; Hipólito; mártires; hagiografía.

\section{[en] Seneca, (Saint) Hyppolitus and Prudentius: a recapitulation}

Abstract. It was already back in the nineteenth century that scholarship established the blatant similarities between Saint Hippolytus' martyrdom as told by Prudentius in Peristephanon 11 and the fate that the character of Hippolytus faces in classical mythology, specially as he is presented in Seneca's tragedy Phaedra. This paper studies the common elements that both texts share as far as content and structure are concerned, and it also analyses the more relevant passages and pays attention to the bibliography published on the subject along the last thirty years. Prudentius builds his poem on the ekphrasis of an actual fresco that pictured Hippolytus' martyrdom told in terms akin to Seneca's version, in order to provide his readers with a new figure: that of the Christian martyr, who blends and overcomes the traditional traits of the epic hero, the tragic hero, and the stoic sage.

Key words: Seneca; Prudentius; Phaedra; Hippolytus; martyrs; hagiography.

Sumario: 1. Introducción: Séneca, Prudencio y la cuestión 'nacional'. 2. Las tragedias de Séneca y Prudencio. 3. El poema 11 del Peristephanon: el martirio de San Hipólito. 4. El Peristephanon 11 de Prudencio y Séneca: las coincidencias. 5. De Prudencio a Séneca: interpretaciones de una relación compleja. 6. Conclusiones.

Cómo citar: Del Río Sanz, E., «Séneca, (San) Hipólito y Prudencio: una recapitulación», Cuad. Filol. Clás. Estud. Lat. 38.2 (2018), 193-213. 


\section{Introducción: Séneca, Prudencio y la cuestión 'nacional'}

Pocos episodios de la cultura occidental resultan tan interesantes y complejos como las tensiones de todo tipo producidas durante los años en los que la cultura cristiana se iba afirmando en el Imperio romano y entraba en colisión con prácticas y tradiciones asentadas durante siglos ante las que la nueva religión se enfrentaba adoptando variadas posturas: la poesía de Prudencio, como bien se sabe, es un ejemplo de síntesis fecunda de esas dos esferas y una muestra de su compatibilidad. Con toda razón ha señalado Romano en un estudio de hace no muchos años $(2011,284)$ que Prudencio persigue con ahínco una mezcla de lo pagano y lo cristiano que ha sido constantemente señalada por la crítica ${ }^{2}$, y que su poesía se mueve en el desvanecimiento de los límites entre una cultura y otra: mientras que en la Roma de la época no había ya lugar para el sincretismo religioso, sí que lo había para el cultural, y la poesía de Prudencio es, entre otras cosas, resultado de la tensión entre dos culturas y síntoma de un proceso de 'maduración' que aún no se había concluido del todo.

Antes de entrar en materia, queremos señalar que este trabajo tiene su origen remoto en nuestra tesis doctoral, leída en 1992 y que se centraba en la pervivencia de las Tragedias de Séneca en la literatura española. En ella dedicábamos unas páginas a la recepción de los textos dramáticos de este autor aún dentro de la propia Antigüedad, en las que nos deteníamos en el caso, ciertamente llamativo, del martirio de San Hipólito, que tal y como lo narra Prudencio en el poema undécimo del Peristephanon guarda evidentes similitudes con la suerte que corre el Hipólito de la mitología clásica, y más en particular con el relato que de ella se hace en la Phaedra de Séneca.

La filología reparó en la citada conexión entre el santo cristiano de cuyo martirio da cuenta Prudencio y el personaje trágico ya a finales del siglo XIX (Sixt 1891 y Weyman 1892), y en los últimos veintitantos años el interés de la crítica por las semejanzas entre ambos textos ha persistido, ya sea en forma de trabajos específicamente dedicados a esta cuestión (Charlet 1993, Gasti 1993, Viscardi 1997, Deproost 1999, Wasiolka 2009) o dentro de estudios más amplios dedicados a una figura, la de Prudencio, cuyas múltiples facetas no dejan de prestarse a variados análisis (Roberts 1989, Malamud 1992, Rivero 1997, Fux 2003).

Lo que nos proponemos en este trabajo es, así, repasar los ejes principales en torno a los que se articulan tanto las conexiones entre ambos textos, el de Séneca y el de Prudencio, como las posturas que los estudios aparecidos en los últimos años han desplegado al respecto, para lo que nos detendremos en los pasajes más relevantes, presentaremos los núcleos principales de las varias discusiones y propondremos una síntesis de las interpretaciones que se han publicado sobre el tema, con el fin de proporcionar una imagen de conjunto de la relación entre el poema cristiano y la tragedia estoica.

A pesar del papel tan relevante que las obras dramáticas de Séneca desempeñaron en el surgimiento del teatro moderno europeo -al ser las únicas tragedias latinas que se conservaron-, en la época inmediatamente posterior, los únicos autores antiguos que mostraron una auténtica admiración por Séneca como escritor fueron los cristianos, sobre todo a partir del siglo III. Esto no es casual, en la medida en que ellos eran,

No podemos detenernos aquí en la amplísima bibliografía sobre esta cuestión; baste recordar que es uno de los rasgos más destacados de la producción de este poeta, como bien han mostrado, entre otros, Rivero García (1997, 193-202), Castro Jiménez (1998) o Cristóbal López (1998). 
en lo literario, anticlasicistas a su manera. A comienzos de este siglo formuló Tertuliano (De anima.20.1) su famoso Seneca saepe noster, pero no debemos aplicar a estos primeros siglos de desarrollo de una literatura cristiana, de forma retrospectiva, la posterior consideración 'cristiana' de Séneca, que como ya demostró Momigliano (1955), es producto del humanismo italiano. Esta admiración, por el contrario, surge de una lectura 'positiva' de la obra en prosa de Séneca: el cristianismo primitivo echó mano, en general, en muchas ocasiones de la filosofía estoica (Mastandrea 1988), y Séneca se constituyó, así, en una fuente imprescindible. Se despertó un interés 'ideológico' hacia él y se le tomó muy en serio como autoridad estoica y pensador filosófico. Pues bien, es en el comienzo de esta valoración positiva, en el principio de esta recuperación de Séneca por los autores cristianos, donde se sitúa Prudencio, y es en él donde podemos rastrear por vez primera una presencia consistente de las tragedias de Séneca en un autor, si no español, sí hispano.

Desde antiguo es tradicional la vinculación establecida entre Prudencio y los autores clásicos ${ }^{3}$, tanto latinos como griegos, hasta el punto de que ya Theodor Poelmann, en el siglo XVI, lo llamó «el Píndaro cristiano» ${ }^{4}$. El hecho de que desde Horacio ningún poeta latino hubiera escrito un corpus tan sustancial de versos líricos, creando incluso nuevas combinaciones estróficas, como veremos, hizo que Bentley le llamara también el «Horacio cristiano» ${ }^{5}$. Algunos, como los editores de la BAC (Rodríguez y Ortega 1981, 51), van más lejos y, no bastándoles la denominación de «Píndaro u Horacio cristiano», afirman que «a Prudencio no se le debe llamar el Horacio o el Virgilio cristiano» a secas, sino «el Horacio, Virgilio, Lucrecio, Píndaro, Juvenal cristiano ${ }^{6}$. No se ha acuñado todavía para Prudencio la denominación de «Séneca cristiano», y no seremos nosotros quienes la defendamos.

Con Séneca comparte Prudencio algo más que una deuda literaria y estética: pesan sobre el poeta cristiano los mismos tópicos sobre la 'españolidad' de Séneca y sobre ese supuesto y prejuiciado 'gusto hispánico' por las escenas sangrientas y por el horror, algo también señalado para Lucano. Y es que, por una parte, Prudencio ha sido considerado tradicionalmente el poeta «español» postclásico por excelencia. Así, Domínguez del Val (1986) se refería a él continuamente como «el poeta español», y en la bibliografía prudenciana encontramos también títulos del mismo tipo (Porebowicz 1921, Rodríguez 1950, Ruysschaert 1968).

Menéndez Pelayo $(1948,301)$ hablaba, por su parte, de «los versos del gran poeta español» al referirse a Prudencio en su Historia de las ideas estéticas en España, y entrando ya en el siglo XX, como con razón señalan Ortega y Rodríguez $(1981,49)$, «más grave es la acusación de que tiene preferencia por escenas horribles y de crudo realismo, al estilo de Ribera y de Goya, Lucano y Séneca... Ahora solo diremos que

Hay numerosos trabajos que explican su relación con los más importantes poetas latinos, a los que se remiten los estudios citados en la bibliografía final y de los que no podemos dar cuenta exhaustiva aquí; el estudio de conjunto más reciente para los dos poetas paganos principales, Horacio y Virgilio, es el de Lühken (2002).

$4 \quad$ En la Praefatio de Aurelius Prudentius Clemens, Theodori Pulmanni Cranenburgii et Victoris Giselini opera emendatus, Antuerpiae, ex officina Christophori Plantini, 1564; la influencia del lírico griego sobre Prudencio ha sido estudiada por Brozek (1954, 1957-1958 y 1971).

Bentley, Horatius Flaccus, Cambridge, 1711, comentario a II, 2, 15.

6 En el mismo empeño de establecer dos 'vidas paralelas' más, no han faltado quienes acudan a las acuñaciones de «el Catulo de los cristianos» y «el Ovidio cristiano» (Rand 1920, 75 y 83), sin perjuicio de que los ecos de uno y otro poetas sean, en efecto, claramente detectables (para Catulo, cf. Rivero 1996 y, más antiguo, Alexander 1930) 
Prudencio tenía que reflejar la atrocidad de los tormentos de sus mártires, y no podía para ello valerse de eufemismos». Porebowicz (1921) da como explicación de las escenas violentas en Séneca y Prudencio la nacionalidad «española», apasionada y violenta, de los dos poetas. Más llamativo es que el editor de Prudencio en Les Belles Lettres, Lavarenne, en su amplio estudio sobre la lengua poética de ese autor (1933, 587), vincule a Séneca y Lucano con Prudencio atribuyendo la «común tendencia a describir escenas de horror» a la procedencia de nacional de todos ellos. Por su parte, Boissier $(1891,143)$ consideraba que el «gusto común» de Prudencio y Séneca por lo «horrible y lo macabro» procede de su común nacionalidad, ya que este «gusto» es típicamente «español». Aún asoman estos prejuicios, aunque de manera más moderada, en estudios como el de Deproost (1999: 180), que a la hora de resumir en sus conclusiones los puntos en común entre Séneca y Prudencio señala que, siendo ambos españoles, compartían gusto por la retórica y espiritualidad exigente.

\section{Las tragedias de Séneca y Prudencio}

La variedad de dimensiones en las que, dentro de la obra de Prudencio, puede advertirse la presencia de las tragedias de Séneca es muy considerable y proporcionar una visión completa al respecto rebasaría los límites de nuestro trabajo. Motivos y paralelos aparte, es la métrica un lugar destacado en el que detectar dicha influencia: a pesar de que el modelo principal es Horacio (Luque 1978, 100 y 236; Rivero 1997, 226-231), Prudencio no siempre se limita a su modelo y se permite bastante libertad, como el empleo en forma monóstica de versos que Horacio solo usa como parte de estrofas: así, utiliza gliconios en la Praefatio de Contra Symmachum II y en Peristephanon 7, los 133 versos de Per. 14 son endecasílabos alcaicos y los 106 del poema 13 de la misma obra son arquiloquios mayores.

Igualmente, a partir de versos clásicos, compone estrofas no clásicas: estrofas de cuatro dímetros yámbicos catalécticos (Cathemerinon 6), de cinco senarios yámbicos (Cath. 7, Peristephanon 10), de tres septenarios trocaicos (Cath. 9, Per. 1), de dos dímetros anapésticos catalécticos (Cath. 10), de cinco trímetros dactílicos hipercatalécticos (Cath. 3, Per. 3), de tres endecasílabos falecios (Cath. 4, Per. 6) y estrofa trística de gliconio, asclepiadeo menor y asclepiadeo mayor en la Praefatio.

Séneca había experimentado también con los metros líricos, usándolos de forma inusitada para la práctica augústea, lo que seguramente influyó en los poetas tardíos, a los que sirvió como ejemplo de experimentación métrica. Puede que los trímetros yámbicos dramáticos de Séneca, predominantes en las partes habladas de las tragedias, estén detrás de la elección de este metro para la larguísima «tragedia» de San Román (Per. 10) aunque para Charlet $(1980,90)$ la técnica de Prudencio en este caso está más cerca de Ausonio y Paulino de Nola que de Séneca.

Pero un caso más seguro de influencia de Séneca puede verse en el uso de glico-

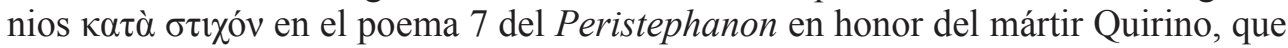
fue arrojado a un río, atado a una rueda de molino, y en los 66 versos de la ya citada Praefatio de Contra Symmachum, II, dedicados a San Pedro. Horacio, en cambio, emplea el gliconio en tres combinaciones distintas, y nunca en forma monóstica.

Pues bien, además de Prudencio, solamente Séneca usa este metro de forma monóstica. De los versos eólicos utilizados por Séneca, el gliconio es menos frecuente 
que el endecasílabo sáfico y el asclepiadeo menor, pero tampoco en Prudencio es uno de los más frecuentes. Prudencio moldea sus gliconios en Horacio, pero mientras este los combina como parte de estrofas, el poeta cristiano los utiliza en forma monóstica. Es en esta utilización donde sigue, probablemente, a Séneca, que es el

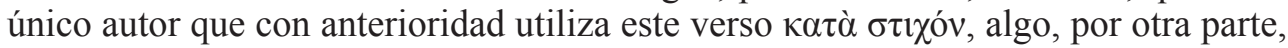
frecuente en él, que suele componer largas tiradas de un mismo verso en sus coros (a veces con versos más cortos intercalados). En todos los casos son intervenciones del coro, de fuerte contenido filosófico ${ }^{7}$, aunque también encontramos otras combinaciones novedosas más allá del uso monóstico ${ }^{8}$.

Métrica aparte, es en el Peristephanon, la obra dedicada a los mártires, donde podemos rastrear la influencia más evidente de las tragedias de Séneca. La obra consta de catorce composiciones dedicadas a mártires, auténticos epinicios de la poesía cristiana, de los cuales los primeros están dedicados a mártires hispanos y los restantes a mártires, en general, romanos. Los rasgos más característicos del teatro de Séneca sugieren, en principio, una influencia general sobre la presentación, esencialmente dramática en algunos casos, de los mártires en el Peristephanon. La confrontación entre mártires y prefectos se puede comparar con el tratamiento de la figura del tirano en las tragedias de Séneca, y podríamos considerar los poemas de Prudencio como el desarrollo de un agón central entre el magistrado romano y el mártir cristiano. Al igual que en las tragedias, en los textos de Prudencio el elemento retórico se manifiesta a medida que la acción avanza a través de escenas de debate con diálogos que descubren la tensión entre actitudes muy opuestas. El énfasis se pone en esos casos más en la escena individual que en la estructura y balance del conjunto.

\section{El poema 11 del Peristephanon: el martirio de San Hipólito}

Pero, dejando aparte estas influencias o características comunes generales, este tono estético común, este mismo tipo de personajes, podemos rastrear una presencia clara de las tragedias de Séneca en uno de los poemas del Peristephanon: el 11, dedicado a San Hipólito, sobre el que la crítica, como ya hemos señalado al principio de este trabajo, ha vuelto en los últimos años.

El poema dedicado a San Hipólito, que Charlet (1993, 156-160) caracteriza muy certeramente como epístola poética elegíaca, surge de la estancia de Prudencio en Roma, del 401 al 403, donde tuvo noticia de los avatares de dicho mártir y visitó

En Hercules furens 875-894, después de cantar en endecasílabos sáficos las hazañas de Hércules, el coro de Tebanas recuerda la llegada final de la muerte; en Medea 75-92 se alaba la belleza de Creúsa; en Thyestes 336403, el coro de ancianos de Micenas critica la ambición de los poderosos y alaba la vida retirada, en Hercules Oetaeus 1031-1130 el coro de mujeres de Etolia canta el sometimiento de todos a la muerte y el carácter perecedero de las cosas.

8 Así, en Phaedra 1130 hay un gliconio detrás de dos asclepiadeos menores y delante de un ferecracio (cambiando el orden de los dos últimos versos de la denominada estrofa asclepiadea cuarta); se intercala en medio de la serie de asclepiadeos menores (Phaedra 783 en la secuencia 764-823); en los coros polímetros de Oedipus y Agamemnon, tenemos también varios gliconios sueltos (Oedipus 407, 410, 492, 710, 718, 729; 481 hipercataléctico, 500 hipercataléctico y con base trocaica, 711 con base trocaica; Agamemnon 611, 625, 842, 863; 848-849 con base trocaica; 605, 606 y 829 hipercatalécticos; 828 hipercataléctico y base trocaica; 635, con la segunda sílaba suelta). En todos ellos se usa una base invariablemente espondaica, como en Horacio. 
su basílica. Los 123 dísticos elegíacos, lo mejor de toda su obra según Lavarenne (1930, 164), están dedicados al obispo Valeriano de Calahorra, con el ruego de que incluya el martirio de San Hipólito en el calendario. Cuenta Prudencio su visita a las capillas y a las catacumbas de Roma (Per.11.1-2 y 7) y, mientras va buscando inscripciones de antiguas hazañas, descubre el sepulcro de Hipólito (Per.11.1719), que había sido partidario del cisma, peruersi dogmatis (Per.11.23), de Novato (Per.11.19-20) ${ }^{9}$. Hipólito, arrastrado ab hoste uesano a la muerte, delante de una gran multitud, plebis multis comitantibus ibat (Per.11.27), se arrepiente y rechaza el cisma (Per.11.29-30).

Después de esto se presenta ante el insano rectori que, harto de matar cristianos en Roma, había salido para acabar con los de los alrededores. Prudencio sitúa ya la acción en la desembocadura del Tíber, junto al mar (Per.11.40 y 47-48). Mientras da las órdenes correspondientes le traen de repente a un anciano encadenado, cabeza del pueblo cristiano (Per.11.80: ipsum christicolis esse caput populis), cuya muerte disuadiría al resto de la multitud (Per.11.81-82). Ante la petición de un nuevo tipo de muerte por parte de los jóvenes que le rodean (Per.11.83-84), el prefecto, fijándose en el nombre del anciano, Hipólito, (Ergo sit Hippolytus, Per.11.87), lo manda atar a las colas de dos caballos que, en sesenta terribles versos a la manera de Séneca, lo arrastran y acaban con su vida.

Después de recoger sus restos, los llevan a Roma y allí los entierran en una cripta, que se convierte en lugar de peregrinación para los cristianos. Tal es la asistencia de fieles que han de ser acogidos en un gran templo cercano, en cuya descripción se detiene Prudencio. En los últimos versos le ruega al obispo Valeriano de Calahorra que incluya esta fiesta en el calendario, el 13 de agosto (Per.11.231-234).

Hasta aquí el breve resumen de la historia contada por Prudencio, pero antes de entrar en el estudio de la cuestión textual es necesario advertir de que la crítica ha formulado sus dudas acerca de la verosimilitud de la écfrasis que contiene Per. 11: así, estudiosos como Malamud (1989, 79-113) la consideran un mero ardid literario de Prudencio y algo meramente ficcional, aunque los autores más recientes se inclinan por conceder credibilidad y base real al relato de Prudencio (Charlet 1993, Fux 2003, Pena 2017) ${ }^{10}$.

Así pues, el martirio de Hipólito en sí no está descrito por ninguna de las fuentes literarias e históricas, los testimonios históricos referentes al personaje son escasos, dispersos, oscuros y, en ocasiones, erróneos, y en las excavaciones del cementerio de San Hipólito no ha aparecido resto ni indicio alguno de la citada pintura ${ }^{11}$. Esto no invalida, sin embargo, la influencia de la citada tragedia de Séneca, ya que la singular descripción de Prudencio está muy cerca de la versión mitológica de Séneca, tanto en estructura como en lenguaje: Prudencio habría tomado como motivo literario una pintura mural para hacer una descripción senequista del mito-martirio, de acuerdo

En la Apotheosis, Prudencio refuta distintas herejías, las de los patripasianos, unionitas, sabelianos, homuncionitas, gnósticos, etc., pero no habla siquiera de la de Novato.

10 Fux (2003, 345-346), en su extenso comentario, recapitula el status quaestionis al respecto: comienza poniendo de relieve lo confuso de los datos sobre Hipólito el mártir, sintetiza lo que se conoce sobre el asunto y recuerda que un Hipólito fue enterrado en una cripta de la vía tiburtina un 13 de agosto, el cual regresó a Roma tras exiliarse en Cerdeña en 235 por la persecución de Maximiano; además, cerca de la desembocadura del Tíber, se encontraba la basílica sepulcral de otro Hipólito; la cripta se ha encontrado, pero sin rastro del fresco.

11 Pena $(2017,267-271)$ recoge y repasa toda la información sobre el Hipólito 'histórico' en relación con el poema de Prudencio. 
con una característica propia del poeta cristiano, ya señalada por el historiador Arce $(1988,206)$, para quien «Prudencio es un poeta excesivamente retórico y literario cuyos esquemas de descripción de iglesias, basílicas y edificios semejantes son perfectamente escolásticos y por tanto no deben ser consideradas sus descripciones como reales»). Por otra parte, Prudencio no se basa en una sola fuente, como ya hemos dicho, y demuestra conocer las versiones que de la muerte de Hipólito ofrecen Virgilio, muy parco en información (Aen.7.761-780), y la más extensa de Séneca ${ }^{12}$, con la que las coincidencias son, como vamos a ver, estrechísimas y no dejan lugar a algo que no sea una 'imitación', por parte del poeta cristiano, aunque con sus características peculiares en las que entraremos más adelante. Veamos, por tanto, cuáles son esas coincidencias entre ambos textos.

\section{El Peristephanon 11 de Prudencio y Séneca: las coincidencias}

En primer lugar, Prudencio relaciona la muerte de Hipólito con el significado de su nombre, lo que no se encuentra en Séneca, pero le sirve para conectar con él. El prefecto pregunta cómo se llama el anciano que acaba de llegar (Quis dicitur?), y cuando le contestan que «Hipólito» (Adfirmant dici Hippolytum), dice: Hippolytus fiar ergo. Prudencio es también amigo de los juegos de palabras, y así, como señala R. Palla en su edición de la obra (1981, 310-312), el último hexámetro dactílico de la Hamartigenia — no es lugar para un análisis detallado, pero señalemos, al menos, que se aparta de la línea lógica de Prudencio al final de esa obra y que tiene algún elemento sorprendente - es un anagrama de su nombre (Ham.966): glorificent, me poena leuis clementer adurat = glorificent me, Aurelio Prudente se clamante (nombre, por cierto, que en ablativo es imposible de encajar en un hexámetro dactílico porque la $e$ de Aurelio es larga).

Ausonio, en el epigrama 41, dirigido contra Méroe, habla de relación entre el nombre de alguien y su muerte o destino, como es el caso de esta vieja borracha que bebe el vino puro, merum, sin mezclar con agua, y cita, entre otros cuya muerte está relacionada con el nombre, precisamente a Hipólito ${ }^{13}$.

Pasando a cuestiones más de contenido, hay que señalar que en el mito clásico la muerte de Hipólito se sitúa junto al mar en todas las fuentes (Ruiz de Elvira 1975, 377-382). La versión de Séneca tiene numerosísimas referencias a él, tanto en los 122 versos en los que interviene el mensajero:

1007: uastum tonuit...mare

1008-1009: ...nullus inspirat salo / uentus

1010: placidumque pelagus propria tempestas agit

1011: Sicula disturbat freta

12 No podemos entrar aquí en la comparación de la muerte de Hipólito en Séneca, Ovidio y Eurípides: cf. Segal (1984).

13 Qui primus, Meroe, nomen tibi condidit, ille /Thesidae nomen condidit Hippolyto. / nam divinare est, nomen componere, quod sit / fortunae et morum vel necis indicium. (...) et tu sic Meroe, non quod sis atra colore, / ut quae Niliaca nascitur in Meroe; / infusum sed quod vinum non diluis undis, / potare immixtum sueta merumque merum. El de Hipólito no es el único caso en el que Prudencio toma el significado del nombre para relacionarlo con su destino o comportamiento: en el poema 3, Santa Eulalia, 'la bien hablada', tiene una intervención brillantísima, desplegando todos los recursos de la oratoria, como corresponde a su nombre. 
1013: saxa cum fluctu tremunt

1014: spuma Leucaten ferit

1015: consurgit ingens pontus

1016: tumidumque monstro pelagus

1018: fluctus haud cursu leui

1020: grauis unda portat

1024: duobus terra comprimitur fretis

1025: en totum mare

1026: undique scopuli adstrepunt

1027: rorat expulso sale

1028: spumat uomitque...aquas

1029: uehitur Oceani freta

1031: undarum globus

1032: et litori inuexit

1033: pontus in terras ruit

1040: sub undis natus

1048: talis extremo mari

1072: turbido rector mari

1081: corniger ponti horridus

como en el posterior lamento de Fedra en el acto quinto y último:

1159: saeue dominator freti

1160: monstra caerulei maris

1161: intimo Tethys sinu

1162: quidquid Oceanus uagis

1163: complexus undis ultimo fluctu tegit.

Prudencio, por su parte, explica detalladamente que la muerte de Hipólito tiene lugar junto al mar, y así dice que el insanus rector perseguía a los cristianos por la zona de la desembocadura del Tíber (Per.11.40: ostia ... per Tiberina).

Precisamente ese día sale de Roma para perseguir a los cristianos de los pueblos de alrededor (Per.11.41-42) y su furia se desata junto a la costa y a los lugares cercanos al puerto, especificando que es el puerto marítimo (Per.11.47-48: protulerat rabiem Tyrreni ad litoris oram / quaeque loca aequoreus proxima portus habet). El prefecto ordena que se arroje al mar enfurecido a unos cuantos, en una barca medio rota (Per.11.70-72):

pellere et in medii stagna profunda freti.

Quos ubi suspectos rabidum male suta per aequor

uexerit et tumidis caesa labarit aquis,

de manera que una bestia, reminiscencia de la que saliendo del mar espanta a los caballos del Hipólito de Séneca, los devore (Per.11.75-76: squamea caenoso praestabit uentre sepulcrum / belua consumptis cruda cadaueribus). Tras el martirio, los fieles que han recogido los restos de Hipólito vuelven a Roma, dejando la desembocadura del Tíber (Per.11.151-152: metando eligitur tumulo locus; ostia linquunt, / Roma placet sanctos quae teneat cineres). 
Otro asunto en el que se pueden detectar coincidencias entre Prudencio y Séneca es, como ya hemos anunciado, la caracterización de los personajes que son responsables del martirio de los cristianos. Así, el prefecto de Per. 11 es presentado como una figura llena de ira, casi fuera de sí:
39: insano rectori
47: protulerat rabiem
52: ardebat
54: iusserat horrendis excrucianda modis.
59-60: lassatis iudex tortoribus ibat / in furias
60: cassa cognitione fremens
63: furens quaesitor
77: haec persultanti

Y esto solo en los cincuenta versos en los que aparece y después de los cuales, por cierto, ya no hay más referencias a él. La caracterización del magistrado en Prudencio coincide, en general, con la del tirano en Séneca (Opelt 1951). El prefecto del primer poema es atrox / ductor aulae mundialis (Per.1.40-41). El que condena a Lorenzo furebat feruido / iudex auarus spiritu (Per.2.166-167), y se enfurece ante el santo cristiano exclamat fremens / praefectus (313-314). En Per. 3, también el pretor habla llevado por la ira: Talibus excitus in furias / praetor ait (Per.3.96-97).

El juez que ordena la muerte de Fructuoso, Augurio y Eulogio en Per. 6, está sentado, violento y furioso (Per.6.34-35: Iudex Aemilianus inminebat, / atrox, turbidus insolens profanus), y cuando Inés ve llegar, en Per. 14, al verdugo con la espada en la mano, exclama con alegría (Per.14.69-70): exulto, talis quod potius uenit / uesanus, atrox, turbidus, armiger.

Este tipo de personaje reúne las mismas características en todas las composiciones del Peristephanon. Esa acentuada ira está en relación con el furor, no solo de Hércules sino de otros personajes de las tragedias, como Casandra, Medea, Tiestes, Atreo, etc.: en el caso de Phaedra es el mar quien recoge el testigo del furor, como puede verse en los versos citados en el caso anterior.

Los caballos se desbocan en ambos casos. En el de Prudencio son dos caballos salvajes que «no conocen las bridas» (89-90: animalia freni / ignara); en el de Séneca, Hipólito intenta contenerlos — no dice cuántos son- tirando de las bridas (1055: Hippolytus artis continet frenis; y 1075-1076: ora nunc pressis trahit / constricta frenis), aunque ni a eso obedecen (1068: inobsequentes protinus freni equi).

Los de Prudencio son azuzados con látigos, gritos y espuelas (106-108: uerbera, uincla, clamoribus, flagellis, stimulis), mientras que el Hipólito de Séneca intenta contenerlos con el látigo (1076-1077: terga nunc torto frequens / uerbere coercet).

Las similitudes se estrechan cuando los caballos se desbocan del todo, aterrorizados tanto los de Séneca como los de Prudencio: 
Phaedra

1055-1056: equos pauidos

1068: inobsequentes frenis equi

1070: rabidos pauidus euexit furor

1079: omni parte terrorem mouens

1082: pauida sonipedes mente exciti

1089: qua timor iussit ruunt

En veloz carrera unos y otros:

\section{Phaedra}

1088: curru leui

1069: rapuere cursum

1074-5: citos currus

1097: celeres...rotae

se salen de camino:

\section{Phaedra}

1069: derrantes uia

1069: rapuere cursum

1074-5: citos currus

1097: celeres...rotae

se resisten contra el yugo:

\section{Phaedra}

1083: luctantur iugo

$\mathrm{y}$, arrojando su carga:

\section{Phaedra}

1084: iactant onus

1090: non suum agnoscens onus

atraviesan todos los obstáculos:

\section{Phaedra}

1071: per scopulos agunt
Per. 11

112: qua tremor exagitant

113: incendit feritas

113: rapit impetus

113: fragor urget
Per. 11

111: prorumptunt alacres

113: cursus uolucer

Per. 11

111: caeco errore feruntur

Per. 11

95: reluctantes bigas

Per. 11

114. nec mobile sentit onus

Per. 11

115: per siluas per saxa ruunt

115-116: non ripa retardat /fluminis

116: (non...) torrens oppositus cohibet

117: prosternunt saepes

117: cuncta obstacula rumpunt

118: prona fragosa petunt

118: ardua transiliunt

El despedazamiento y dispersión de los restos del mártir-héroe por el campo tienen una estrecha correspondencia entre los once versos de Séneca y los trece de Prudencio, lo que puede comprobarse tras el análisis de las dos narraciones. En la de Séneca (1093-1104), los restos ensangrientan el campo en una gran extensión (1093: late cruentat arua), de los cuales la cabeza golpea rebotando contra las pie- 
dras (1094-1094: inlisum caput / scopulis resultat). Los matorrales le arrancan los cabellos (1094: auferunt dumi comas) y una piedra le destroza el rostro (1095: ora durus pulcra populatur lapis), mientras todo el cuerpo de Hipólito se llena de heridas (1096: perit multo uulnere infelix decor). Después, las ruedas revuelcan los miembros ya moribundos (1097: moribunda celeres membra pervoluunt rotae) y un tronco, con una estaca a medio quemar, retiene al cuerpo en medio de las ingles, con la punta erguida (1098-1099: raptum truncus ambusta sude / medium per inguen stipite ingesto tenet), para que a continuación los caballos desgarren el cadáver (11011102: [equi] et pariter moram / dominumque rumpunt). Por fin, los matorrales, las espesas y erizadas zarzas, acaban de despedazarlo (1102-1103: inde semianimem secant / uirgulta, acutis asperi uepres rubis), y no hay arbusto que no se quede con una parte del cuerpo (1104: omnisque ruscus corporis partem tulit).

También en Prudencio (cuyo relato ocupa los versos 119-132) es el campo el que va arrancando pequeños pedazos del cuerpo deshecho de Hipólito (119-120: scissa minutatim labefacto corpore frusta / carpit...ager), y también el cuerpo se queda retenido, en este caso colgando una parte de lo alto de las rocas (121: pars summis pendet scopulis) y otra enganchada a los matorrales (121: pars sentibus frondes). Los fragmentos del cadáver tiñen de rojo las zarzas (122: parte rubent frondes) y empapan de sangre la tierra (122: parte madescit humus). Se insiste en la presencia de la sangre: los miembros están ensangrentados (126: tracti membra cruenta uiri) y manchan rocas (127: rorantes saxorum apices uidi) y matorrales (128: purpureasque notas uepribus inpositas). La sangre, el rojo, en fin, lo tiñe todo (130: minio russeolam saniem) y los miembros se extienden a lo largo del campo (132: membra per incertos sparsa iacere situs.

Los dos autores ofrecen, como vemos, el mismo tratamiento del despedazamiento del cuerpo de Hipólito, aunque con alguna lógica diferencia. Prudencio tiñe concienzudamente de rojo la escena: rubent frondes (122), rorantes saxorum apices (127), purpureas notas (128), minio russeolam saniem (130); todo ello apoyado por: madescit humus (122), membra cruenta (126); frente a un solo caso en Séneca: late cruentat arua (1093). Este se detiene en explicar cómo el cuerpo se va desgarrando en zarzales y rocas: así, frente a dumi (1094), truncus (1098), sude (1098), stipite (1099), uirgulta (1103), uepres (1103), rubis (1103), ruscus (1104) y scopulis (1094), lapis (1095) de Séneca, solo tenemos sentibus (121), frondes (122), uepribus (128) y scopulis (121), saxorum (127) en Prudencio (in sudibus en el 143). Séneca detalla las partes del cuerpo: caput (1093), comas (1094), ora (1095), inguen (1099); Prudencio, en cambio, se refiere a todas ellas genéricamente en estos versos: pars (121), pars (121), parte (122), parte (122); en los siguientes (133-150) se 'deleitará' en detallar las partes en que ha sido dividido el cuerpo. Séneca se detiene en el escenario físico: piedras, arbustos, matorrales, etc.; y utiliza verbos que denotan especialmente violencia, como rumpunt (1102), secant (1102), populatur (1095) y cruentat (1093). Prudencio, por su parte, se esfuerza por pintar de rojo ese cuadro.

El elemento más genuinamente senecano (Segal 1984, 157) se refleja también en Prudencio: en las dos obras tiene lugar la descripción de dolentum sedulus labor, la recomposición de los restos del cadáver por un leal grupo de seguidores (Prudencio, 133-150; Séneca, 1105-114, pronunciados por el mensajero).

Los caros gressu sequentes (133) en Prudencio siguen el rastro del mártir deuia quo fractum semita monstrat iter (134), aturdidos por la tristeza y llorando, maerore attoniti atque oculis rimantibus ibant (135). Los criados de Séneca siguen, igual- 
mente, errant per agros (1105), el rastro de Hipólito, per illa qua distractus Hippolytus loca / longum cruenta tramitem signat nota (1106-1107), que, en este caso, es señalado por perros, maestae domini membra uestigant canes (1108).

Los seguidores del santo llenan sus vestidos con uisceribus laceris (136). Este último y macabro detalle no pasa sin una particularización más patética: un seguidor recoge la caput niueum y en su tierno regazo reuerendam / canitiem confouet, y otro los hombros, las manos mutiladas, los brazos, las muñecas, las rodillas y las piernas: hic umeros truncasque manus et bracchia et ulnas / et genua et crurum fragmina nuda legit (139-140). Séneca es menos explícito en la descripción: passim ille colligitur / et confertur (113-114), aunque en su intervención final Teseo enumera las distintas partes del cuerpo al intentar, sin éxito, recomponerlo (1258-1260):

fortis hic dextrae locus,

hic laeua frenis docta moderandis manus

ponenda: laeui lateris agnosco notas.

Prudencio describe la ansiedad de los cristianos en guardar tantas reliquias como sea posible, y así con trapos y esponjas limpian la sangre de Hipólito, todavía caliente, de los zarzales y de la arena: Prudencio la compara con el rocío de la mañana. Los trapos empapados en sangre, en particular, son reminiscencias del mundo de las reliquias (Delehaye 1933, 120ss.) y no tienen paralelo en la Phaedra de Séneca (Per.11.141-144):

Palliolis etiam bibulae siccantur harenae, ne quis in infecto puluere ros maneat.

Si quis et in sudibus recalenti aspergine sanguis insidet, hunc omnem spongia pressa rapit.

Los seguidores cristianos de San Hipólito tienen más suerte que sus equivalentes en Séneca, ya que culminan con éxito su tarea. En el campo no queda ningún resto del cuerpo de Hipólito, algo sobre lo que Prudencio quiere llamar especialmente la atención, ya que para ello se detiene nada menos que en seis versos de los 17 (Per.11.145-150).

Los amigos de Hipólito en la versión de Séneca ven frustrado su empeño por la extensión del área sobre la cual sus restos están esparcidos y no pueden recoger el cuerpo entero, de lo que dan constancia el coro, cuando le dice a Teseo que sepulte lo antes posible los dispersa membra, y Teseo mismo en su impresionante intervención en la que no reconoce a Hipólito entre la masa de restos (1247-1249 y 1265-1267). Teseo abraza los miembros y quodque de nato est super (1254), e intenta recomponer el cuerpo (1256-1258), pero se queja de que no está entero y ordena a los criados que sigan buscando (1278-1279). Pero mientras en Prudencio se entierra el cuerpo (151: metando eligitur tumulo locus; 173: seruat ossa sepulcro), en Séneca se habla de incineración (1113: ad supremos rogos y 1277: regii flammam rogi. Teseo enuncia dos maldiciones que, según Grimal, darían a entender que se concibe la inhumación como deshonrosa frente a la incineración (1279: istam terra defossam premat y 1280: grauisque tellus impio capiti incubet), expresando la segunda un deseo contrario a la fórmula habitual, sit tibi terra leuis. El entierro del cuerpo es el foco cristiano real de interés una vez que el martirio ha tenido lugar, y esto proporciona una parcial 
explayación para detenerse en lo que solamente es una breve sugerencia en Séneca. Prudencio encuentra aquí el necesario puente para volver a su descripción de los monumentos de la Roma cristiana contemporánea, donde los restos de Hipólito están sepultados, junto con todos los otros restos que Prudencio ha mencionado orgullosamente al comienzo del poema.

El lugar de entierro de Hipólito está en las catacumbas romanas, a las que los peregrinos vienen anualmente para celebrar su festividad. La descripción que hace Prudencio es similar a la que hace Teseo en Hercules furens de su bajada al Hades. Dice Teseo que el camino no está a oscuras desde el principio, sino que una tenue luz penetra hacia abajo (668-672), y Prudencio habla de un camino en pendiente, (uia prona), con escalones en espiral, al que llega también la luz del sol. En ambos pasajes la bajada a las catacumbas/Hades está iluminada por una dudosa luz del día. El camino, que no es difícil de seguir, según Teseo (675: nec ire labor est; ipsa deducit uia), conduce a unos espacios amplios con estancias vacías (673: hinc ampla uacuis spatia laxantur locis), de la misma manera que en Prudencio, avanzando fácilmente (159: progressu facili), se llega a una galería en la que se abren distintas estancias (Per.11.163-164: Quamlibet ancipites texant hinc inde recessus / arta sub umbrosis atria porticibus).

Aunque el subterráneo parezca grande en su amplia entrada, es estrecho para tanta gente como acude (213-214: angustum tantis illud specus esse cateruis / haud dubium est, ampla fauce licet pateat), y la concurrencia se alberga en un templo que se alza cerca de las catacumbas, con cuya descripción, que tiene sus concomitancias con la descripción que del palacio de Pélope hace el mensajero en Thyestes, cierra Prudencio su poema.

\section{De Prudencio a Séneca: interpretaciones de una relación compleja}

La refundación cristiana de Roma requiere nuevos héroes: los mártires cristianos. En nuestro caso, Prudencio ve posibilidades en la lectura de Séneca, y libremente moldea su versión del martirio a partir de sus tragedias. La adaptación a un contexto cristiano, como hemos visto, es clara: hay consistentes correspondencias de vocabulario y pensamiento, aunque no imitaciones verbales exactas ni extensas, como ya dejó claro Charlet $(1993,160)$ y han suscrito estudiosos posteriores.

La narración senecana de la muerte de Hipólito, frente a las fuentes clásicas, especialmente Eurípides y Ovidio, pone un especial énfasis en el aspecto monstruoso del suceso y en crear un ambiente de horror en torno al mismo (Segal 1984). Esta composición es, así, uno de los ejemplos más claros en toda la obra de Prudencio de lo que Lavarenne (1945, XIV-XVI) denomina «reconciliación del cristianismo y de la cultura clásica», hecho básico en nuestra civilización occidental y en el que, según el editor francés, radica el interés de la obra del poeta cristiano. Para Rodríguez (1981, 40-41) «pocos han deseado tan ardientemente la unión en el orden cultural del cristianismo y del paganismo como nuestro poeta. Es cierto que él ha ridiculizado con mayor sarcasmo que Comodiano a los dioses de Roma y que ha acusado con mayor tesón que Boecio a los padres paganos. Pero esto no le conduce a la condenación de toda la antigüedad clásica, sino que aspira más bien a cristianizarla y a iluminarla con la luz del Evangelio. Quiere cumplir el ansia del Medioevo». 
A lo largo de los últimos veinticinco años se han sumado varios estudios centrados en este poema de Prudencio y que tratan su relación con Séneca, entre los que destaca el de Jean-Louis Charlet (1993), que aborda prácticamente todos los aspectos relevantes e influye decisivamente en los trabajos posteriores. El estudio de Charlet (1993) está dedicado a los dos poemas elegíacos de Prudencio: Per. 8 y 11. En las páginas que dedica a nuestro poema (Charlet 1993, 142-160), reconstruye lo que se sabe de la vida del Hipólito de Roma (1993, 142-144), remitiendo a la no escasa bibliografía al respecto, y subraya $(1993,145)$ que está claro que Prudencio parte del epigrama de Dámaso. Ante estudios para entonces recientes como el de Malamud (1989), para quien la extensa écfrasis de Prudencio es exclusivamente un ejercicio literario, Charlet (1993, 146-147) se plantea sus dudas sobre si Prudencio acoge tradiciones orales preexistentes o se abandona a su propia labor de ficción poética. Incluso, se sigue interrogando Charlet $(1993,148)$, aun admitiendo que hubiera un fresco realmente pintado en las paredes de la catacumba que Prudencio evoca haber visitado, ¿cuánto de lo que relata está en la imagen que ve y cuánto es evocación a partir de la misma? Tras no muy larga pero convincente argumentación, Charlet se inclina a considerar la descripción una trasposición poética de la imagen que el autor realmente vio. Charlet (1993, 148-149) no tiene duda de que ha habido una confusión entre los dos Hipólitos, pero descarta que el martirio de Hipólito sea una invención de Prudencio, porque el público al que se dirige, empezando por el obispo Valeriano a quien va dedicado el poema, no hubieran acogido fácilmente, para el caso de un martirio, un relato novedoso y ficcional.

Respecto a la evidente conexión entre el tratamiento del martirio y la figura clásica de Hipólito, Charlet $(1993,150)$ considera posible que Prudencio recurriera a Séneca u Ovidio para su reescritura del martirio, o que ya estuvieran esos elementos del relato pagano en la pintura que describe, o, en fin, que Prudencio detectase en la poesía antigua elementos susceptibles de ser interpretados alegóricamente como prefiguración del martirio.

Con Ovidio, aclara pronto Charlet $(1993,151)$, no hay parentesco directo alguno, mientras que con Séneca sí: la misma estructura de díptico en los dos poetas, y también en los dos autores los mismos elementos en cada una de las dos partes del díptico; pero, y esto es fundamental ninguna expresión verbal original común (1993, 151): el eco más claro sería (1993, 151 n. 43) entre Sen.Phaedr.1090 ([currus] non suum agnoscens onus) y Perist.11.114 (nec cursus uolucer mobile sentit onus). Esta similitud estructural, por un lado, pero llamativa ausencia, por otro, de paralelos verbales, indicaría que Prudencio habría pretendido, más bien que una imitación o un homenaje, una aemulatio, el establecimiento de cierta rivalidad con el modelo que elige como referencia, para dejar clara la distancia entre uno y otro Hipólitos (Charlet 1993, 151), lo que quedaría aún más patente gracias a la diferencia entre lo que ocurre con los restos mortales de cada Hipólito (Charlet 1993, 151-152).

Charlet, por último, dedica unas cuantas páginas (1993, 156-160) a caracterizar genéricamente la composición de Prudencio, que dirigida al obispo Valeriano, constituiría una epístola poética, y más concretamente, por su metro, elegíaca, como los precedentes de Propercio 4, 8 y desde luego las Tristes y Pónticas, y similar a las contemporáneas de Ausonio y Claudiano, sin olvidar cierta dimensión etiológica (al dar razón del origen del culto al santo) que la emparentaría con los Fastos $^{14}$.

\footnotetext{
No es así extraño que Fux $(2003,347)$ califique esta composición como la más 'alejandrina' del Peristephanon.
} 
Las palabras finales de Charlet $(1993,166)$ recuerdan de manera muy apropiada la riqueza y complejidad del texto prudenciano, cuya finalidad, más allá de otras cuestiones ideológicas, es esencialmente poética: «le grand art avec lequel le poète a fondu la narration dans la description et réciproquement, s'il fait par moments le désespoir de l'archéologue ou de l'exégète, comble le lecteur avide de poésie."

Poco tiempo después de este fundamental trabajo apareció el estudio de Gasti, que conecta en varios asuntos con las ideas de Charlet, las cuales lleva más allá en cuanto a la conexión Séneca-Prudencio. Para Gasti (1993, 215), solo en Peristephanon 11 el senequismo de Prudencio es una decisión consciente y hasta programática: el resto de ecos, coincidencias, reminiscencias etc. son anecdóticas, esporádicas e insuficientes para hablar de dependencia directa.

Gasti (1993, 215-216) establece tres niveles de 'senequismo' en Peristephanon 11: los paralelos léxicos directos, el común dramatismo retórico y la analogía de estructura narrativa. Gasti $(1993,217)$ persigue valorar (no demostrar: eso se da por descontado) el uso que Prudencio hace de su conocimiento de la tragedia senecana, y suscribe el citado juicio de Charlet que ve en Prudencio el empeño de construir una aemulatio rivalizante y. que «vuole fare opera di poesia, prima che di ricostruzione storica».

Gasti confecciona la que es la lista más larga, con diferencia, de semejanzas entre los dos Hipólitos (señalando, además de conexiones claras y directas otras analogías menos evidentes y que en algún caso rayan la simple coincidencia).

En resumen, serían las siguientes: (1) ambos personajes se nos presentan en situación de aislamiento (el uno por su voto de castidad, el otro por haberse adherido a la herejía cismática de Novato (Gasti 1993, 218 y 221); (2) la ambientación junto al mar del relato de Prudencio resulta incongruente o innecesaria (Gasti 1993, 219), y solo se explica por su relación con la versión de Séneca; (3) de los dos Hipólitos hay una imagen a la que acude Prudencio: por un lado, el fresco del mártir que se describe en Peristephanon 11, por otro, el fresco del Hipólito pagano que había en el templo de Diana en el Aventino y que también Prudencio describe en un pasaje de otra obra a menudo señalado por los estudiosos (Symm. 2, 53-56); (4) la figura del insanus rector es un claro paralelo dl tirano senecano (Gasti 1993, 220), y sus apariciones son descritas en términos cuyo campo léxico es alusivo al furor (Gasti 1993, 222); (5) los prólogos de ambos relatos pueden considerarse atípicos: el de Séneca por su falta de conexión con los acontecimientos que luego tienen lugar en la propia tragedia; el de Prudencio tampoco conecta con la historia de Hipólito; en ambos hay además una ambientación que alude a la figura del protagonista y a la escena capital de despedazamiento (Gasti 1993, 220-221); (6) los dos Hipólitos se 'autocondenan' en cierta manera antes de serlo efectivamente (Gasti 1993, 223), por su actitud de arrostrar las consecuencias de una decisión cuyo desenlace prevén; (7) las últimas palabras de los dos personajes suponen una afirmación de su valentía respectiva ante el desenlace fatal (Gasti 1993, 224), y preceden inmediatamente al despedazamiento, donde se localizan las semejanzas textuales más significativas (Gasti 1993, 225); (8) en ambos casos se alude a la fortaleza de su animus, y se invoca a los 'padres' de cada uno (Teseo y Cristo) como recuerdo de su dimensión heroica (Gasti 1993, 225); (9) las muertes, ejemplares en los dos, expían y purifican la elección vital previa, que para los dos ha sido heterodoxa (el abandono del trato humano y la inclinación herética (Gasti 1993, 226); (10) en fin, ambos cadáveres despedazados son objeto de intento de recomposición, con resultado desigual, eso sí (Gasti 1993, 226-227). 
Como síntesis, Gasti $(1993,228)$ subraya que la estructura de ambos textos sitúa la experiencia que padece el protagonista encerrada dentro de dos momentos 'fuertes' literaria y conceptualmente; la muerte ejemplar de ambos les concede acceso al mundo 'ejemplar' (natural, sobrenatural) que ambos habían elegido.

El trabajo de Viscardi (1997) comienza haciendo hincapié en la importancia que reviste la ambientación de la acción en las catacumbas, que proporciona el clima de revelación espiritual que reina en el poema y que, para esta estudiosa, es clave para su interpretación $(1997,360)$, «comme si l'imaginaire du poète était stimulé par la présence des reliques». Viscardi $(1997,377)$ apuesta por existencia real del fresco descrito por Prudencio y subraya los efectos de 'realidad' (de enargeia) ${ }^{15}$ que la écfrasis produce sobre el lector del texto $(1997,363$ y 366-367). Viscardi $(1997,367)$ admite que el martirio padecido por San Hipólito es inusitado y que su fuente indiscutible es Séneca, para pasar a continuación a resumir las semejanzas entre ambos relatos, que cifra en cuatro $(1997,368)$, a saber: la situación de la acción del martirio en un escenario rocoso y marino, el papel central de los caballos desbocados, el hecho del cadáver destrozado en pedazos y la recomposición ulterior del cuerpo del difunto. Para Viscardi (1997, 368-371) estaríamos ante una elección consciente por parte de Prudencio de reutilizar un texto pagano, con el fin de plantear un juego literario deliberado en el que se busca la síntesis entre héroes paganos y mártires cristianos, frente a otros autores que contraponen unos y otros.

Como elementos que merecen destacarse en cuanto a la relación de un texto y otro, Viscardi, al igual que otros críticos se detiene en el furor de los verdugos prudencianos $(1997,371)$ y en la importancia que, a su juicio, merece la idea y el término via: los recomponedores del cadáver de San Hipólito marchan por un camino difícil y tortuoso de evidente connotación espiritual, mientras que los caballos de Séneca por via ancha y fácil, que sería también la via equivocada del, en su momento, cismático Hipólito (Viscardi 1997, 372-373).

La formulación del título del artículo de Deproost (1999), en la que aparecen los términos 'sabiduría' y 'tragedia', apunta directamente a la idea general que preside su estudio, a saber, la del diseño por parte de Prudencio de un nuevo tipo de héroe trágico dotado de sapientia; el subtítulo («la réception de Sénèque dans le Peristephanon liber») no deja lugar a dudas de que es gracias al recurso a Séneca como Prudencio consigue alcanzar su objetivo.

Deproost comienza a contrario, podríamos decir, ya que atenúa todo lo señalado por la crítica hasta el momento sobre Séneca en Prudencio, para reconocer luego que, con todas las reservas que se puedan poner, la influencia es innegable. Sin embargo, Deproost $(1999,161)$ matiza la importancia de los ecos verbales, ya que lo fundamental en la conexión entre ambos poetas sería el encuadramiento estoico: Deproost $(1999,161)$ hace especial hincapié en los puntos en común entre la libertas de la que hacen gala y hasta exhibición los mártires de Prudencio y el ideal estoico, e insiste en que lo central en la influencia de la tragedia de Séneca, más que la literalidad de los ecos verbales y las decisiones métricas, es la reutilización, el dar un nuevo 'bon usage' estético al drama estoico, en el que, se reitera Deproost, más importante que lo verbal es el arte de la puesta en escena y los desbordamientos violentos y macabros.

Tras hacer suyas las conclusiones de Charlet sobre la escasez de ecos verbales directos y asumir también que Prudencio lleva a cabo una aemulatio con rerspecto

En lo que coincide con Bertini $(2013,1)$. 
al modelo de Séneca, Deproost $(1999,163)$ defiende la que es su tesis principal, a saber, que lo que persigue Prudencio es identificar al mártir cristiano con el sabio estoico y con el héroe trágico unificados, con el fin de completar y corregir la definición virgiliana del héroe épico ${ }^{16}$.

La construcción de esta nueva figura literaria y cultural es posible, explica Deproost (163-167) gracias a los puntos en común que comparten sabio estoico y mártir cristiano: ambos profesarían en lo que Deproost denomina «una escuela de belleza y de libertad», a la que hay que asociar el aprendizaje de la muerte, la impasibilidad y acaso cierto regodeo en el propio sufrimiento que puede llevar, incluso, a la búsqueda de la muerte dadas ciertas circunstancias.

Deproost $(1999,169)$ detecta en Séneca (en De providentia) ya la intuición, la prefiguración de la lucha del hombre contra la adversidad como verdadero spectaculum (dial. 1, 2, 8), y pone de manifiesto $(1999,178)$, coincidiendo con otros estudiosos, cómo los mártires de Prudencio y sus perseguidores evolucionan de manera análoga a los actores de un espectáculo. Y así, argumenta Wasiolka $(2009,179)$, las tragedias ponían al alcance de Prudencio los modelos de humanidad desaforada y de desbordamientos emocionales que necesitaba para dar al combate de los mártires su justa dimensión, pero es que además le proporcionaban un proceso de puesta en escena cercanísimo al que tenemos en el Peristephanon, ya que el mito dramatizado es una especie de laboratorio que trabaja con los mismos elementos que Prudencio quiere utilizar.

Coincidirían también Séneca y Prudencio en su psicología no exclusivamente trágica, ya que ambos, frente a la fatalidad que el héroe trágico arrostra inevitablemente, levantan la figura del sabio/mártir, y son así los dos 'antitrágicos'. Así, el Séneca estoico y tragediógrafo le sirve a Prudencio para que los nuevos valores de su nuevo héroe no supongan la inversión total del héroe épico virgiliano, gracias al apoyo que le brinda la figura del sabio estoico (Deproost 1999, 179-180).

Los paralelos que Deproost $(1999,172-173)$ despliega entre sabio estoico y mártir cristiano pasan también por coincidencias lingüísticas a la hora de ser descritos por uno y otro y atañen además a la cuestión de la elocuencia: si el mártir es un héroe dotado de elocuencia «vertiginosa e inagotable», Séneca también establece un vínculo entre retórica y ética, y reivindica «el derecho de la elocuencia a la emoción». Esa elocuencia extraordinaria estará siempre subordinada, sin embargo, al servicio de la verdad, que es lo que ocurre con la retórica de los mártires y lo que puede aplicarse, aunque de manera indirecta, a los discursos de los personajes trágicos de Séneca (Deproost 1999, 174).

Deproost $(1999,176)$ caracteriza así la influencia de Séneca en Prudencio como algo menos evidente en el nivel verbal, pero más profundo por las afinidades ideológicas y estéticas entre ambos. El modelo poético de Prudencio es sobre todo Virgilio, no hay que olvidarlo, pero la confluencia con Séneca, que se debe al ascetismo que ambos comparten, permite comprender mejor la entrega resignada y hasta impasible de los mártires frente a la figura del héroe épico virgiliano, cuyas cualidades son otras.

También Wasiolka (2009) adelanta en su título una de las conclusiones: si habla de «un manifiesto poético interno» es porque quiere poner de relieve la dimensión

Wasiolka $(2009,103)$ suscribe también la caracterización clara de los mártires prudencianos en general y de Hipólito en particular con los rasgos de un héroe épico. 
de declaración estética que puede leerse en el tratamiento de San Hipólito por parte de Prudencio debido, claro está, a la relación que establece con el modelo trágico de Séneca. Con su interés dirigido sobre todo a lo literario, Wasiolka arranca, significativamente, restando peso a la importancia de la historicidad de San Hipólito, y en la primera frase de su trabajo afirma $(2009,89)$ que «del Hipólito histórico no sabemos casi nada». Prudencio no perseguiría diferenciar lo legendario de lo histórico, y el suplicio que describe $(2009,89-90)$ «tient sans doute davantage de la légende que de la réalité historique», por más que fuera probablemente la imaginación popular la que asoció el mártir al personaje mitológico, y dio lugar a un fresco, descrito por Prudencio, cuya existencia real admite esta estudiosa $(2009,90)^{17}$.

Wasiolka $(2009,91)$ asume y amplía la idea de Charlet de la aemulatio pretendida por Prudencio y la lleva más allá: estaríamos ante todo un manifiesto poético, mediante el que Prudencio afirma la nueva poesía que desea crear, una nueva literatura dirigida a destinatarios refinados y conocedores de los códigos que desea superar con su creación poética.

Sin embargo, Wasiolka $(2009,92)$ subraya que la cuestión de cómo Prudencio reescribe a Séneca ha atraído menos atención crítica que la écfrasis del martirio, y admite que una razón para ello es que no son tantas las correspondencias verbales, para lo que se muestra de acuerdo con Charlet (1993) y Deproost (1999). Y si Deproost ponía el peso de la afinidad Séneca-Prudencio en cuestiones más ideológicas que literarias, Wasiolka le da importancia, sobre todo, a lo estructural-narrativo por encima de lo léxico: Prudencio retoma el esquema narrativo del monólogo del mensajero de la Fedra de Séneca, lo que da lugar a las siguientes coincidencias (Wasiolka 2009, 92-94): (1) las palabras de desafío que pronuncian ambos Hipólitos antes de que los caballos arranquen (Gasti 1993, también); (2) el relato en ambos casos comienza por el momento en el que los caballos se salen del camino previsto, continúa con el despedazamiento y concluye con la búsqueda de los fragmentos; (3) la inclusión de palabras directas de ambos Hipólitos; (4) el paisaje llamativamente rocoso.

Con todo, junto con la semejanza en el desarrollo narrativo, se pueden ver también paralelos estilísticos, que residirían en el uso del presente de narración, en la evocación de sensaciones y emociones, en el recurso a la amplificatio, y en el carácter visual del relato: en general, para Wasiolka $(2009,97)$, Prudencio adoptaría la 'estética barroca' de Séneca, cuyos aspectos más anticlásicos y desequilibrados quedarían justificados y compensados en Prudencio por la cuestión del servicio a la fe: es la fe la que justifica lo que sin ella son excesos.

De este modo, partiendo de la idea de aemulatio y rivalidad con Séneca que plantea Charlet para Prudencio, Wasiolka $(2009,101)$ reajusta y reformula su interpretación: Prudencio escribe no tanto contra Séneca como gracias a Séneca; no se trata de un desafío literario, sino de un uso particularmente hábil de la cultura clásica. En todo caso, y si se quiere hablar de rivalidad, esta no sería tanto estilística o literaria como de sentido o mensaje centrado en el significado, diametralmente opuesto, que se otorga a las muertes de cada uno de los Hipólitos: la del mártir tiene sentido gracias a Dios, la del pagano es la típica caída trágica; la muerte del pagano es consecuencia y símbolo de sus errores, la del mártir es signo de su redención (Wasiolka 2009, 101-103). La misma contraposición, como ya ha sido señalado, se daría para

En sintonía con esta idea, Fux $(2003,367)$ explica que «Prudence opère une retractatio littéraire de la Phèdre de Sénèque (...) sans se borner à refléter naïvement une légende». 
Wasiolka en el final que tiene cada uno de los cuerpos: el funeral de uno es imposible por lo desperdigado de los miembros; el del otro es casi eternamente celebrado gracias a la recolección y conservación de las reliquias.

Así, con el recurso a Séneca como precedente literario lo subversivo del nuevo heroísmo cristiano no se define gracias a un intertexto épico o hímnico, acaso demasiado previsibles y fuente de tensiones, sino gracias a la relectura de un referente trágico que enriquece, sintetiza y transforma le modelo pagano.

\section{Conclusiones}

Como se ha podido comprobar, la red de conexiones que puede establecerse entre Séneca y Prudencio a partir de Peristephanon 11 y su relato del martirio de San Hipólito es rica y compleja. La decisión de integrar en una epístola elegíaca un relato basado en la contemplación de un fresco, en una écfrasis de cuya autenticidad algunos han dudado pero que hoy se admite generalmente como verídica, nos lleva a conjeturar acerca de la actitud de Prudencio al respecto. Creemos que es muy probable que, ante la representación pictórica de un martirio evidentemente inspirado en la figura del Hipólito pagano, Prudencio pensara 'se non è vero, è ben trovato'. Por mucho que el fresco existiera realmente, en un Prudencio que se muestra tan hábil y fecundo en el manejo de la tradición poética que le precede, además de ver al devoto cristiano queremos ver al poeta sofisticado altamente consciente de las convenciones literarias y de los ardides narrativos. $\mathrm{Y}$ es en estas coordenadas, las literarias y poéticas, como mejor se explica el empeño de este poeta, que, como ya hemos visto, gracias al entronque con la tragedia estoica de Séneca contribuye a la construcción de un nuevo ideal humano y literario, el del heroico mártir cristiano que se superpone, superándolos, al héroe épico, al héroe trágico y al sabio estoico.

\section{Referencias bibliográficas}

Alexander, F. (1936), «Beziehungen des Prudentius zu Ovid», WS 54, 166-173.

Allard, P. (1885), «L'hagiographie au IVe siècle: martyres de St. Hyppolyte, de St. Laurent, de St. Agnès, de St. Cassien d'après les poèmes de Prudence», Revue des Questions Historiques $37,353-405$.

Arce, J. (1979), Caesaraugusta, ciudad romana, Zaragoza: Guara.

Bertini, F. (2013), «Ippolito martire e Fedra boccacciana», Dioniso 3, 209-224.

Boissier, G. (1981), La fin du paganisme, París: Hachette.

Brozek, M. (1954), «De Prudentio-Pindaro latino I», Eos 47, 107-141.

Brozek, M. (1958), «De Prudentio-Pindaro latino II», Eos 49, 123-150

Brozek, M. (1971), «De scriptoribus latinis antiquis Pindari laudatoribus et aemulis», Eos 59, 101-107.

Castro, M.D. (1998), «Sincretismos en el uso de la mitología en la obra de Prudencio», $C F$ $C(L) 15,297-312$.

Charlet, J.L. (1980), L'influence d'Ausone sur la poésie de Prudence, Aix-en-Provence: Presses Universitaires de Provence.

Charlet, J.L. (1993), «Les poèmes de Prudence en distiques élégiaques», en Catanzaro, G. y 
Santucci, F. (eds.), La poesia cristiana latina in distici elegiaci. Atti del convegno internazionale (Assisi 20-22 marzo 1992), Asís: Accademia properziana del Subasio, 135-166. Cristóbal, V. (1998), «Horacio y Prudencio», CFC(L) 15, 157-169.

Delehaye, H. (1933), Les origines du culte des martyrs, Bruselas: Bureaux de la Société des Bollandistes.

Deproost, P.A. (1999), «Le martyre chez Prudence: sagesse et tragédie. La réception de Sénèque dans le Peristephanon Liber», Philologus 143, 161-180.

Domínguez del Val, U. (1986), Estudios sobre literatura latina hispano-cristiana. 1: 1955 1971, Madrid; Fundación Universitaria Española.

Fux, P.Y. (2003), Les sept Passions de Prudence (Peristephanon 2.5.9. 11-14), Friburgo: Éditions Universitaires de Fribourg.

Gasti, F. (1993), «La "passione” di Ippolito: Seneca e Prudenzio», QCTC 10, 215-228.

Lavarenne, M. (1933), Étude sur la langue du poète Prudence, París: Société française d'imprimerie et de librairie.

Lavarenne, M. (1943-1951), Prudence. Oeuvres, París, Les Belles Lettres.

Lühken, M. (2002), Christianorum Maro et Flaccus: zur Vergil- und Horazreception des Prudentius, Gotinga: Vandenhoeck und Ruprecht.

Luque Moreno, J. (1978), La evolución acentual de los versos eólicos en latín, Granada: Universidad de Granada.

Malamud, M. (1989), A poetics of transformation: Prudentius and classical mythology, Ithaca: Cornell University Press.

Mastandrea, P. (1988), Lettori cristiani di Seneca filosofo, Brescia: Paideia.

Menéndez Pelayo, M. (1948), Historia de las ideas estéticas en España (4ª ed), Madrid: CSIC, I, 297-301.

Momigliano, A. (1955), «Note sulla leggenda del cristianesimo di Seneca», en Id., Contributo alla storia degli studi classici, Roma: Edizioni di Storia e Letteratura, 13-32.

Opelt, H. (1951), Der Tyrann als Unmensch in der Tragödie des L. A. Seneca, Friburgo: U. de Friburgo.

Ortega, A. y Rodríguez, I. (1981), Prudencio. Obras completas, Madrid: B.A.C.

Palla, R. (1981), Prudencio. Hamartigenia, Pisa: Giardini.

Pena, M.J. (2017), «Hipólito-Virbio, San Hipólito y Pirro Ligorio», $C F C(L)$ 37, 265-282.

Porebowicz, E. (1921), «L'espagnolisme d'A. Prudence», Eos 25, 1-12.

Rand, K. (1920), «Prudentius and christian humanism», TAPhA 51, 71-83.

Rivero, L. (1996), «Ecos catulianos en los poemas de Prudencio», AEF 19, 443-455.

Rivero, L. (1997), La poesía de Prudencio, Huelva: Universidad de Huelva.

Roberts, M. (1993), Poetry and cult of the martyrs. The liber Peristephanon of Prudentius, Ann Arbor: U. of Michigan Press.

Rodríguez, I. (1950), «Prudencio, poeta de la hispanidad», Helmantica 1, 83-101.

Romano, P. (2011), «Il rapporto tra cultura pagana e cristiana nell'opera di Prudenzio», RCCM 53, 263-284.

Ruiz de Elvira, A. (1975), Mitología clásica, Madrid: Gredos.

Ruysschaert, F. (1968), «Prudence: l'espagnol poète des deux basiliques romaines de S. Pierre et de S. Paul», Rivista di Archeologia Cristiana 42, 267-286.

Segal, C. (1984), «Senecan baroque: the death of Hippolytus in Seneca, Ovid and Euripides», TAPhA 114, 311-325.

Sixt, G. (1892), «Des Prudentius Abhängigkeit von Seneca und Lucan», Philologus 51, 501-506. Viscardi, G. (1997), «La vision du martyre de saint Hippolyte ou la mortification transfigurée: Prudence, Peristephanon 11», Latomus 56, 360-381. 
Wasiolka, J. (2009), «Prudence, Peristephanon 11, v. 105-152: la passion d'Hippolyte d'après Sénèque, un manifeste poétique interne», en Galand-Hallyn, P. y Zarini, V. (eds.), Manifestes littéraires dans la latinité tardive: poétique et rhétorique (Actes du colloque international de Paris, 23-24 mars 2007), París: Institut d'Études Augustiniennes, 89-107.

Weyman, C. (1891), «Seneca und Prudentius», en Commentationes Woelflinnianae, Leipzig, 281-287. 